\title{
FORMAS DE MECANIZAÇÃO E MANEJO DO SOLO PARA A CULTURA DA BATATA II - DESENVOLVIMENTO VEGETATIVO
}

\section{LARISSA R. SAITO ${ }^{1}$, SIDNEI O. JADOSKI ${ }^{2}$, MARCIO F. MAGGI ${ }^{3}$, LIVIA L. S. R. SALES $^{4}$, ADRIANO SUCHORONCZECK ${ }^{5}$}

\begin{abstract}
RESUMO: O objetivo da pesquisa foi estudar os efeitos do manejo com diferentes formas de preparo do solo, tipos de resteva e infestação do solo com o fungo Trichoderma harzianum Rifai sobre as características de componentes do dossel vegetativo da cultura da batata. $\mathrm{O}$ experimento foi desenvolvido em Guarapuava-PR, em delineamento inteiramente casualizado, com parcelas subsubdivididas, em um esquema fatorial 4 × 5 x 2, com quatro repetições. Para o fator 1, foram avaliadas quatro formas de mecanização do preparo do solo $(\mathrm{P})$ : preparo-base (escarificação e sulcamento) - P1; preparo-base mais grade niveladora - P2; preparo-base mais enxada rotativa - P3 preparo-base mais grade niveladora e enxada rotativa - P4. No fator 2, utilizaram-se restevas de aveia, milho, trigo, feijão e uma testemunha sem resteva. $O$ fator 3 constitui-se da infestação ou não infestação do solo com o fungo T. harzianum. As variáveis comprimento da maior haste e índice de área foliar (IAF) foram afetadas pelo tratamento com o fungo T. harzianum. O IAF apresentou também comportamento diferenciado ao longo do ciclo em relação à cobertura do solo com resteva de milho. O maior revolvimento do solo no preparo inicial reduz a produção de massa seca da parte aérea da cultura da batata.
\end{abstract}

PALAVRAS-CHAVE: preparo do solo, tipos de resteva, Trichoderma harzianum, infestação, área foliar.

\section{FORMS OF MECHANIZATION AND SOIL MANAGEMENT FOR THE POTATO CULTURE II - CROP VEGETATIVE DEVELOPMENT}

\begin{abstract}
The objective was to study the effects of management with different forms of tillage, reservoir types and soil infestation with the fungus Trichoderma harzianum Rifai over the characteristics of canopy components of potato. The experiment was structured in a completely randomized design with split plots in a $4 \times 5 \times 2$ factorial with four replications. For factor 1 it was evaluated four types of tillage - $(\mathrm{P})$ : base tillage (scarifiation and harrowing furrowing) - P1, base tillage plus disc harrow - P2, rotary hoe plus basic tillage - P3 and base tillage plus disc harrow and rotary hoe - P4 . In Factor 2 it was used the stubble of oats, corn, wheat, beans and a control without stubble. The Factor 3 was constituted by no infestation or infestation of soil with the fungus $T$. harzianum. The variable length of the longest stem and index of leaf area (IAF) were affected by the treatment with the fungus $T$. harzianum. IAF presented also different length over the cycle in relation to the soil cover with corn stubble. The highest soil inversion in the initial tillage reduces the production of dry matter of the potato crop shoot.
\end{abstract}

KEYWORDS: soil preparation, types of stubble, Trichoderma harzianum, infestation, leaf area.

\footnotetext{
${ }^{1}$ MSc em Agronomia - Universidade Estadual do Centro Oeste - Unicentro. Campus Cedeteg, Rua Simeão Camargo Varela de Sá, n.3. CEP:85040-080. Guarapuava-PR. E-mail: larissaromaosaito@ gmail.com.

${ }^{2}$ Eng $^{\circ}$ Agrônomo, Prof. Dr., Departamento de Agronomia, Universidade Estadual do Centro Oeste - Unicentro. Campus Cedeteg, Rua Simeão Camargo Varela de Sá, n.3. CEP:85040-080. Guarapuava-PR. E-mail: sjadoski@unicentro.br.

${ }^{3}$ Eng ${ }^{\circ}$ Agrícola, Dr., Programa de Pós-Graduação em Engenharia de Sistemas Agroindustriais, Universidade Estadual do Oeste do Paraná - Unioeste. Cascavel PR. E-mail: mfmaggi@unioeste.br.

${ }^{4}$ MSc em Agronomia - Universidade Estadual do Centro Oeste - Unicentro. Campus Cedeteg. Guarapuava-PR. E-mail: livialu2005@hotmail.com.

${ }^{5}$ Graduando em Agronomia, Universidade Estadual do Centro Oeste - Unicentro. Campus Cedeteg. Guarapuava-PR. E-mail: adriano_agri@hotmail.com.

Recebido pelo Conselho Editorial em: 27-6-2011
}

Aprovado pelo Conselho Editorial em: 21-4-2013 


\section{INTRODUÇÃO}

A cultura da batata apresenta alto grau de sensibilidade às condições gerais de cultivo, sendo o processo de mecanização e o preparo inicial do solo fundamentais para um adequado desenvolvimento vegetativo e produção. FERNANDES et al. (2006) destacam que o plantio de batata em solo com o preparo reduzido, em que é realizado um menor número de operações de revolvimento anterior ao plantio, devido a não ser realizado lavração e gradagem, pode constituir uma alternativa viável, sendo possível economizar combustível, diminuir o tempo necessário ao desenvolvimento da cultura, preservando as características agronômicas do solo.

De acordo com FURLANI \& SILVA (2009), sistemas que mantenham cobertura com resteva vegetal sobre o solo, principalmente durante os períodos mais críticos com baixa quantidade de precipitação pluvial, estão sendo cada vez mais utilizados pelos produtores devido à crescente preocupação com a conservação do solo e armazenamento de água. MARTINS FILHO et al. (2009) destacam que os melhores resultados dos cultivos dependem diretamente das técnicas de conservação do solo e da água, essenciais para manter as características químicas, físicas e biológicas dos solos, sendo que, ao adicionar palha ao solo, observa-se um controle mais eficiente destas características. Conforme IZIDORIO et al. (2005), estes são aspectos que reforçam o efeito benéfico exercido pela palhada sobre a conservação do solo e que beneficiam o desenvolvimento e a produção das culturas.

O fungo Trichoderma harzanium Rifai é um forte colonizador da palha (LISBOA et al., 2007) e, além de serem utilizados em controle de patógenos, os fungos deste gênero são também utilizados como agentes promotores de crescimento. Esse mecanismo refere-se ao desenvolvimento das plantas de forma geral, incluindo os efeitos benéficos na germinação de sementes, na emergência e no desenvolvimento das plântulas, e na produção de grãos e frutos (HARMAN, 2000). Com relação aos efeitos deste fungo, ALTOMARE et al. (1999) descrevem que os nutrientes solubilizados se tornam disponíveis para a absorção pelas raízes, reduzindo-se, desta forma, a necessidade de adubação para a planta.

Dentre as ações mais destacadas do Trichoderma, SAITO et al. (2009) salientam a atuação como agentes de biocontrole e, em alguns casos, como promotores de crescimento, o que os torna uma potencial alternativa como prática integrante no manejo de culturas agrícolas; entretanto, os autores destacam a necessidade de pesquisas continuadas na busca de aprofundar conhecimentos para utilização adequada e definição clara de suas ações e efeitos.

Desta forma, objetivou-se avaliar os efeitos de formas de preparo mecanizado do solo, a presença de diferentes tipos de restevas e a introdução de cepa comercial do fungo T. harzianum no solo, sobre características de desenvolvimento vegetativo da cultura da batata.

\section{MATERIAL E MÉTODOS}

O estudo foi conduzido em área experimental do Departamento de Agronomia, no Câmpus da Universidade Estadual do Centro-Oeste - Unicentro, em Guarapuava - PR. O clima da região é classificado, conforme metodologia de Köppen (1928), como Cfb - subtropical mesotérmico úmido. Os dados climáticos no período do experimento foram obtidos da Estação Meteorológica da Unicentro/Iapar, localizada a aproximadamente $200 \mathrm{~m}$ da área experimental.

O solo do local é classificado como Latossolo Bruno distroférrico. A área foi mantida em pousio por aproximadamente 03 anos, tendo sido cultivado trigo no inverno anterior ao plantio da batata. Aproximadamente 90 dias anteriores à instalação do experimento, foram coletadas amostras de solo da camada de 0-20 cm para análise química de solo (Tabela 1). Aos 60 dias antes do plantio, foi realizada a calagem, visando a elevar o $\mathrm{pH}$ do solo para aproximadamente 6,2, com incorporação por grade pesada. 
TABELA 1. Características químicas do solo da área experimental. Guarapuava-PR. Experimental area soil characteristics. Guarapuava-PR.

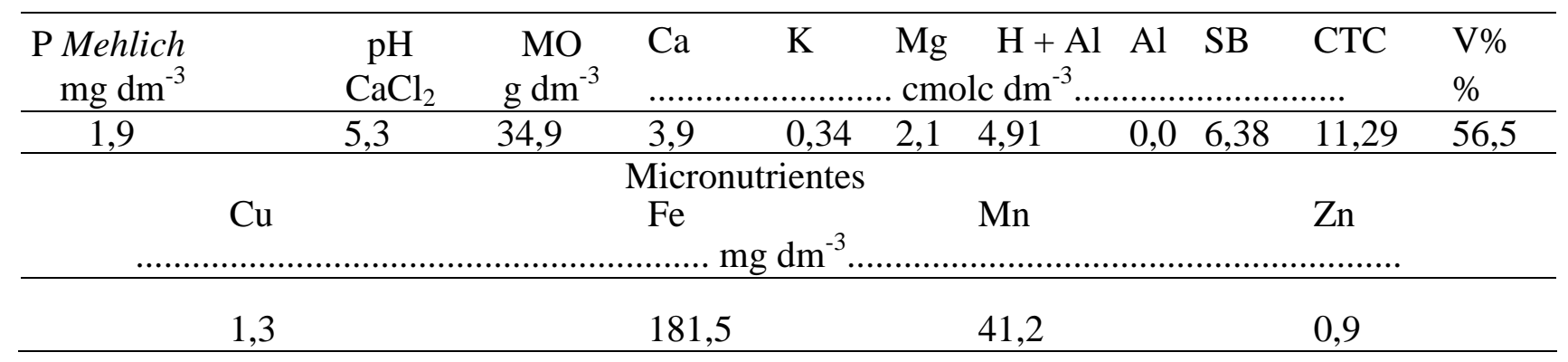

O plantio da batata foi realizado no dia 19 de dezembro de 2009, utilizando-se da cultivar Ágata, com semente certificada de primeira geração (G1), produzida pela EMBRAPA, na estação experimental de Canoinhas-SC. O plantio dos tubérculos-semente do tipo 2 (diâmetro entre 40 e 50 $\mathrm{mm}$ ) foi realizado distribuindo-se os tubérculos manualmente em sulcos com profundidade de aproximadamente $0,18 \mathrm{~m}$.

$\mathrm{O}$ experimento foi estruturado em delineamento inteiramente casualizado, em parcelas subsubdivididas, em fatorial 4 × 5 × 2, com 4 repetições. $O$ fator 1 foi avaliado na parcela principal, sendo composto por quatro diferentes formas de preparo do solo. O fator 2 foi avaliado na subparcela, com cinco diferentes tipos de resteva como cobertura do solo, sendo um deles sem resteva (testemunha). O fator 3 foi avaliado na subsubparcela, consistindo na infestação ou não do solo com T. harzianum.

Para cada tratamento avaliado, a unidade experimental foi composta por quatro fileiras de plantas com 3,5 de comprimento e espaçadas com 0,8 m entre fileiras e 0,25 m entre plantas. A densidade de plantio foi de 50.000 tubérculos por hectare. Nas unidades experimentais, as duas fileiras centrais foram consideradas como área útil, e as duas fileiras laterais, como bordadura.

No fator 1, o preparo (P1) foi o mais simples, denominado preparo-base, e consistiu na escarificação da área e na utilização de sulcador para a abertura dos sulcos e posterior plantio. No preparo (P2), foi feita a escarificação da área, a passagem de grade niveladora e utilização de sulcador para a abertura dos sulcos e posterior plantio. O preparo (P3) foi realizado com escarificação da área, passagem de enxada rotativa e utilização de sulcador para a abertura dos sulcos e posterior plantio. No preparo (P4), efetuou-se escarificação da área, passagem de grade niveladora e de enxada rotativa, e utilização de sulcador para a abertura dos sulcos e posterior plantio, sendo este o preparo que, em geral, é utilizado pelos bataticultores da região.

No fator 2, as quantidades de resteva (palha) utilizadas foram estimadas de acordo com a média remanescente das culturas de aveia, milho, trigo e feijão em lavoura convencional. A palha foi depositada em área já totalmente escarificada para posterior incorporação. A resteva utilizada foi coletada e deixada para secar em local protegido até a obtenção de massa seca (kg) constante, para posterior pesagem da quantidade indicada de massa seca $(\mathrm{kg})$ por unidade de área $\left(\mathrm{m}^{2}\right)$ para cada tipo de palha utilizada. Utilizou-se de $4 \mathrm{t} \mathrm{ha}^{-1}$ de resteva de aveia-preta (R1), considerando-se resultados obtidos por SCHUCH et al. (2008). O volume da resteva de milho (R2) e de trigo foi definido de acordo com estudos realizados por DINIZ (2007), utilizando-se de6 e 3t ha ${ }^{-1}$, respectivamente. $\mathrm{O}$ volume de resteva de feijão (R4) foi de $3 \mathrm{t} \mathrm{ha}^{-1}$, considerando-se estudos realizados por TEIXEIRA et al. (2009). No manejo sem resteva (R5), foram realizados apenas os preparos do solo.

Para o fator 3, a infestação do solo com T. harzianum (I) foi realizada por aspersão no sulco, no momento do plantio, com $1,0 \mathrm{~L} \mathrm{ha}^{-1}$ de inoculante, e no dia da amontoa, com $0,5 \mathrm{~L} \mathrm{ha}^{-1}$, no solo, próximo à base das plantas, acompanhando a fileira de plantio. $\mathrm{O}$ inoculante produzido por Itaforte BioProdutos, em 15 de novembro de 2009, possuía concentração de 2 x $10^{9}$ conídios viáveis $\mathrm{ml}^{-1}$ de 
cepa especial de T. harzianum, em inerte orgânico, com função de manter a viabilidade dos conídios.

Após a distribuição dos tubérculos nos sulcos, aplicou-se o fungicida com ingrediente ativo (i. a.) Pencycuron e inseticida (i. a.) Clorpirifós, visando a proteger os tubérculos, durante o desenvolvimento inicial, observando-se que o fungicida não foi aplicado nas unidades experimentais dos tratamentos onde se utilizou infestação com o fungo T. harzianum.

A adubação foi realizada no sulco, na data do plantio, antecedendo a distribuição dos tubérculos-semente. Foram aplicadas 3,3 ton ha $^{-1}$, utilizando a fórmula NPK 4-14-8, com uma adubadora mecânica de distribuição linear. A adubação foi definida considerando dados de JENKINS \& MAHMOOD (2003) e resultados de pesquisas apresentados em JADOSKI et al. (2010).

A emergência de plantas ocorreu aos 12 dias após o plantio. A amontoa, com elevação da camada de solo formando um camalhão em ambos os lados da fila de planta, foi realizada aos 18 dias após a emergência (DAE), com auxílio de uma enxada rotativa, objetivando estimular a tuberização, evitar o esverdeamento dos tubérculos por exposição à luz, reduzir a infestação por plantas daninhas e reduzir os riscos de ataque por fitopatógenos e insetos.

O tratamento fitossanitário foi realizado com pulverização de fungicidas de forma preventiva para as doenças de pinta-preta (Alternaria solani) e requeima (Phytophthora infestans). Foram realizadas duas aplicações de produto à base de Mancozeb para pinta-preta e de produtos à base de Azoxystrobin, Tebuconazole e Iprodione, para requeima. Todas as parcelas foram pulverizadas, independentemente do tratamento com infestação do solo com $T$. harzianum, pois, segundo informações prestadas pelo fabricante, este fungo não é afetado pelos tratamentos fitossanitários utilizados no experimento.

O controle de insetos foi realizado com alternância entre produtos à base de Tiametoxam, Carbaril, Cloripirfós e Lambda-cialotrina, com média de duas aplicações semanais. Ambos os produtos inseticidas e fungicidas são registrados para a cultura da batata e foram utilizados nas doses recomendadas. O controle de plantas invasoras foi realizado manualmente quando necessário.

O ciclo de cultivo no campo desde o plantio até a dessecação para colheita foi de 95 dias. Foram realizadas avaliações de massa seca da parte aérea das plantas aos 41 e aos 73 DAE. Foram avaliadas cinco plantas em cada subsubparcela, que foram postas a secar a $65{ }^{\circ} \mathrm{C}$ em estufa ventilada até atingir peso constante. As determinações não destrutivas de número de hastes por planta, comprimento da maior haste e índice de área foliar, foram realizadas durante todo o ciclo de cultivo, em intervalos quinzenais, a partir dos 12 DAE até 72 DAE, em dez plantas de cada subsubparcela. Estas plantas foram selecionadas ao acaso no início do desenvolvimento vegetativo, sendo marcadas com estacas etiquetadas fixadas próximo às plantas.

A determinação do número de hastes por planta foi realizada por contagem, considerando apenas aquelas originadas a partir de brotos que emergem da batata-semente (hastes principais), nas plantas previamente demarcadas. O comprimento da haste principal foi determinado por meio de uma fita métrica graduada em mm, sendo medida a partir do solo até a extremidade apical da haste.

A avaliação da área foliar, fisiologicamente ativa, desconsiderando-se as folhas já senescidas, foi realizada medindo-se o comprimento $(\mathrm{C})$ e a largura $(\mathrm{L})$ de todas as folhas da planta e inserindo-se os valores na equação $(A F=0,2798$ x $(\mathrm{L}$ x C $)+71,267)$ apresentada por SILVA et al. (2008). O índice de área foliar - IAF, foi determinado considerando a razão entre a área foliar do dossel e a área de solo disponível para planta, conforme espaçamento de plantio.

A avaliação estatística dos dados foi realizada por análise de variância e teste de comparação de médias, pelo método de Tukey, em nível de 5\%, e teste (t) de Student para o caso de pares de médias, utilizando-se do software estatístico ASSISTAT versão 7.5 beta. 


\section{RESULTADOS E DISCUSSÃO}

Observou-se que, aos 12 DAE, a infestação com T. harzianum ocasionou incremento do IAF em plantas nos diferentes preparos do solo (Tabela 2), ocorrendo também diferenças significativas entre os diferentes tipos de resteva aos 27 DAE (Tabela 3).

TABELA 2. Índice de Área Foliar $\left(\mathrm{m}^{2} \mathrm{~m}^{-2}\right)$ de planta de batata aos 12 DAE, considerando os fatores formas de preparo e infestação do solo com Trichoderma harzianum. Leaf area index $\left(\mathrm{m}^{2} \mathrm{~m}^{-2}\right)$ of potato plants 12 DAE consiering the factors preparation methods and soil infestation with Trichoderma harzianum.

\begin{tabular}{lcc}
\hline \multicolumn{1}{c}{ Formas de preparo } & $\begin{array}{c}\text { Não Infestado com } \\
\text { T. } \text { harzianum }\end{array}$ & $\begin{array}{c}\text { Infestado com } \boldsymbol{T} . \\
\text { harzianum }\end{array}$ \\
\hline Preparo-base (PB) (P1) & $0,69 \mathrm{Ba}$ & $1,59 \mathrm{Aa}$ \\
PB + Grade niveladora (P2) & $0,71 \mathrm{Ba}$ & $1,58 \mathrm{Aa}$ \\
PB + Enxada rotativa (P3) & $1,00 \mathrm{Ba}$ & $1,92 \mathrm{Aa}$ \\
PB + Grade niveladora+ Enxada rotativa (P4) & $0,94 \mathrm{Ba}$ & $1,77 \mathrm{Aa}$ \\
\hline DMS para colunas & & 0,5309 \\
\hline DMS para linhas & & 0,4219 \\
\hline
\end{tabular}

Médias seguidas pela mesma letra maiúscula na linha ou minúscula na coluna não diferem estatisticamente entre si, pelo teste de Tukey, ao nível de 5\% de probabilidade de erro.

Nesta avaliação aos 12 DAE, percebe-se que onde houve infestação com o fungo no solo, as médias de IAF foram superiores, independentemente da forma de preparo do solo. Esse efeito indica ação positiva do T. harzianum sobre o desenvolvimento foliar no estádio inicial da cultura.

Neste caso, é provável que o fungo esteja exercendo um auxílio por sua ação de interação com o sistema radicular, melhorando a absorção de nutrientes, independentemente da forma de preparo utilizada, enquanto neste estádio, as plantas cultivadas sem a presença do fungo dependam quase que exclusivamente dos nutrientes restantes na batata-semente, tendo ainda reduzida contribuição dos nutrientes do solo. ALTOMARE et al. (1999) descrevem que a promoção de crescimento em plantas por $T$. harzianum reside em sua capacidade de solubilização de nutrientes importantes para a planta.

TABELA 3. Índice de Área Foliar $\left(\mathrm{m}^{2} \mathrm{~m}^{-2}\right)$ das plantas de batata aos $27 \mathrm{DAE}$, considerando o fator tipo de resteva. Leaf Area Index $\left(\mathrm{m}^{2} \mathrm{~m}^{-2}\right)$ of potato plants 27 DAE considering the factor kind crop residues.

Médias seguidas pela mesma letra não diferem estatisticamente entre si, pelo teste de Tukey, ao nível de 5\% de probabilidade de erro.

Conforme dados da Tabela 3, verifica-se que, aos 27 DAE, os cultivos em resteva de aveia e de milho resultaram no menor e maior valor de IAF, respectivamente, evidenciando que a resteva da cultura anterior pode afetar o desenvolvimento do dossel vegetativo da planta de batata. Em relação à aveia, este dado vem somar-se aos apresentados por JADOSKI et al. (2009), que verificaram efeitos negativos da resteva desta cultura sobre a cultura da batata, mais notadamente em relação à qualidade dos tubérculos produzidos, sendo o resultado atribuído à maior ocorrência de fitopatógenos no dossel vegetativo e nos tubérculos. 
Em uma análise temporal, as diferenças para o fator infestação com T. harzianum ocorreram aos 12; 57 e 72 DAE (Figura 1). Derivando-se a equação, verifica-se que o desenvolvimento máximo do índice de área foliar ocorreu aos 42 DAE (63 DAP), com IAF de 7,5 $\mathrm{m}^{2} \mathrm{~m}^{-2}$ (Figura 1). Este valor é superior ao verificado por COELHO et al. (2009), que observaram IAF entre 5 e 7 em plantas da cultivar Ágata. Os autores, contudo, salientam que, em diferentes condições de cultivo, manejo e características climáticas do local, esta cultivar tem apresentado desenvolvimento do dossel vegetativo amplamente variável.

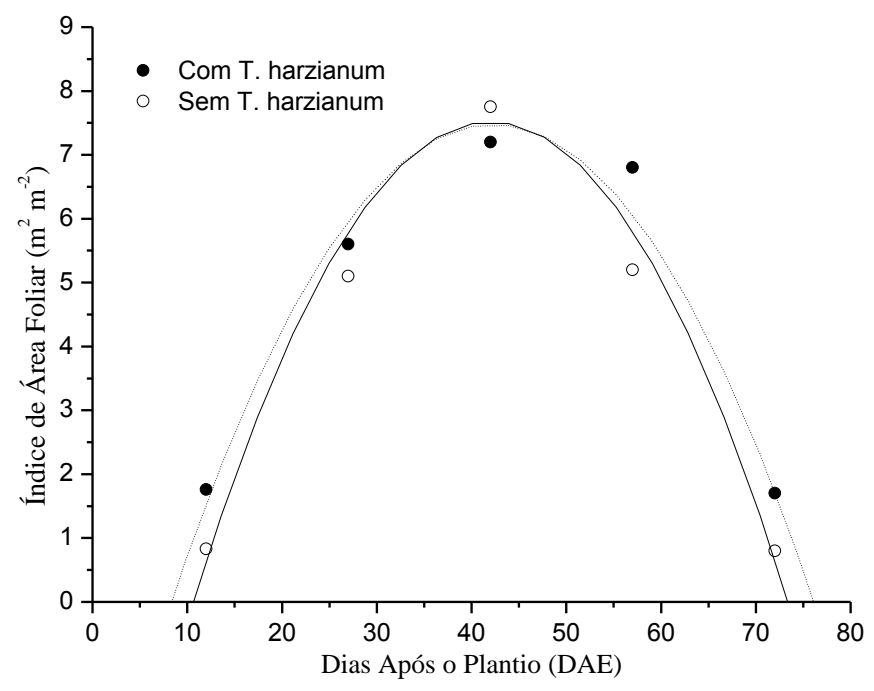

FIGURA 1. Comportamento médio do índice de área foliar $\left(\mathrm{m}^{2} \mathrm{~m}^{-2}\right)$ das plantas de batata submetidas ao cultivo com $\left(\mathrm{Y}=-0,0065 \mathrm{X}^{2}+0,55 \mathrm{X}-4,125 ; R^{2}=0,98\right)$ e sem $(\mathrm{Y}=$ $\left.0,00716 X^{2}+0,601 X-5,477 ; \quad R^{2}=0,97\right)$ infestação do solo com $T$. harzianum. Guarapuava - PR. Average behavior of the leaf area index $\left(\mathrm{m}^{2} \mathbf{m}^{-2}\right)$ of potato plants subjected to cultivation with $\left(Y=-0,0065 \mathrm{X}^{2}+0,55 \mathrm{X}-4,125 ; R^{2}=0,98 ;\right)$ and without $\left(Y=-0,00716 X^{2}+0,601 X-5,477 ; R^{2}=0,97\right) T$. harzianum soil infestation . Guarapuava - PR.

Na figura 1, observa-se que as plantas cultivadas com infestação de T. harzianum no solo mantiveram IAF igual ou superior ao cultivo sem infestação, em todo o ciclo vegetativo. Este resultado está associado tanto pelo maior desenvolvimento do dossel vegetativo, quanto pela redução da senescência e manutenção da coloração verde das folhas por mais tempo, especialmente naquelas do terço inferior do dossel.

De acordo com MELO et al. (2003), o número de folhas da planta decresce rapidamente a partir do máximo valor de IAF, dado o envelhecimento das folhas baixeiras, até o total desaparecimento das folhas no final do ciclo. A manutenção de maior área foliar aos 70 DAE é um fator positivo, pois conforme JENKINS \& MAHMOOD (2003), este é um estádio em que a capacidade fotossintética está sendo reduzida, enquanto os tubérculos ainda estão em processo de crescimento.

A variável massa seca da parte aérea (MSE) não apresentou diferenças estatísticas significativas na avaliação realizada na fase de pleno desenvolvimento vegetativo (41 DAE), em função dos tratamentos estudados, sendo verificado valor médio de 57,2 gr planta $^{-1}$. Entretanto, são verificados efeitos significativos da forma de preparo do solo e da infestação com T. harzinaum sobre a MSE, na avaliação realizada no estádio de maturação dos tubérculos, aos 73 DAE, (Tabela 4). 
TABELA 4. Massa seca da parte aérea $\left(\mathrm{g}_{\text {planta }}{ }^{-1}\right)$ de batata, considerando os fatores formas de preparo do solo e infestação do solo com $T$. harzianum, realizada aos 73 DAE. Potato shoot dry matter $\left(\mathrm{g}\right.$ plant $\left.^{-1}\right)$ considering the factors tillage and soil infestation with $T$. harzianum at 73 DAE.

\begin{tabular}{|c|c|c|c|}
\hline \multicolumn{2}{|c|}{ 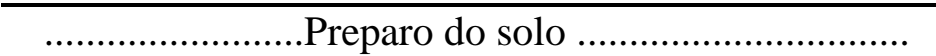 } & \multicolumn{2}{|c|}{... Infestação por T. harzianum .... } \\
\hline Preparo base $(\mathrm{P} 1)$ & $54,77 \mathrm{a}$ & Não infestado & $44,79 \mathrm{~b}$ \\
\hline $\mathrm{P} 1$ + Grade niveladora $(\mathrm{P} 2)$ & $55,28 \mathrm{a}$ & Infestado & 55,79 a \\
\hline $\mathrm{P} 1+$ Enxada rotativa $(\mathrm{P} 3)$ & $48,73 \mathrm{ab}$ & & \\
\hline $\mathrm{P} 1+$ Grade niveladora+ Enxada rotativa $(\mathrm{P} 4)$ & $42,39 \mathrm{~b}$ & & \\
\hline DMS & 11,345 & & 4,150 \\
\hline
\end{tabular}

Fator 1 - Médias na mesma coluna, seguidas pela mesma letra, não diferem estatisticamente entre si, pelo teste de Tukey, ao nível de $5 \%$ de probabilidade do erro.

Conforme os dados apresentados na Tabela 4, aos 73 DAE, os preparos de solo P1 e P2, com menor mobilização, por não utilizar enxada rotativa, proporcionaram maior produção de massa seca da parte aérea das plantas, quando comparados ao preparo P4. Este efeito sobre o incremento do acúmulo de massa seca no dossel das plantas, aos 73 DAE, demonstra que o manejo inicial do solo pode influenciar características evidenciadas pela planta inclusive nos estádios mais avançados do ciclo de cultivo. O preparo mecanizado com menor movimentação do solo para o cultivo de batata foi pesquisado por GHAZAVI et al. (2010), que observaram maior desenvolvimento das plantas nestas condições, destacando-se os efeitos positivos da redução do revolvimento do solo sobre aspectos de fertilidade e retenção de água.

Resultados similares aos efeitos das formas de preparo do solo foram verificados, também, para a infestação com o fungo $T$. harzianum (Tabela 4). Verifica-se que, aos 73 DAE, as plantas cultivadas em solo infestado com o fungo apresentaram médias de MSE superiores ao do cultivo sem infestação. Estes resultados, expressando os efeitos da presença do fungo nos estádios finais do ciclo vegetativo, possivelmente, estão relacionados com o aumento do efeito da atividade do fungo devido ao maior tempo para sua expansão desde a infestação inicial do solo, somado ao maior IAF verificado na presença do fungo nesta data.

Considerando os efeitos de T. harzianum sobre o crescimento das plantas, HARMAN (2000) destaca que este fungo possui a capacidade de aumentar a área radicular das plantas, proporcionando maior absorção de nutrientes e, com isso, favorecendo o desenvolvimento vegetativo da planta. DONOSO et al. (2008) enfatizam resultados de pesquisas que demonstram que a aplicação de $T$. harzianum favoreceu plantas de diferentes culturas hortícolas que se apresentaram mais vigorosas, com maior massa úmida e seca, e com melhor desenvolvimento do sistema radicular. Baseados em resultados de pesquisa, WINDHAM et al. (1986) consideraram este fungo como um claro indutor do crescimento vegetativo e de acúmulo de biomassa em plantas.

O número médio de hastes, avaliado no pleno desenvolvimento vegetativo aos 42 DAE, foi de 3,46 hastes planta $^{-1}$, não se constatando diferenças estatísticas significativas ou ocorrência de interações entre os fatores experimentais. Neste caso, salienta-se que o número de hastes é uma característica considerada como altamente associada àquelas inerentes à cultivar e, segundo SOUZA (2003), os fatores que mais comumente afetam o número de hastes na planta são as condições de brotação do tubérculo-semente, densidade de plantio e época de cultivo. FERNANDES et al. (2010) encontraram médias gerais de 4,2 hastes por planta e salientaram que a cultivar Ágata, assim como a Asterix, apresentam número de hastes por planta, em geral, superiores às demais cultivares que atualmente são cultivadas, como Atlantic e Monalisa.

A avaliação do comprimento da maior haste demonstrou efeito de interação entre os fatores formas de preparo do solo e infecção com T. harzianum aos 12 DAE (Tabela 5). Nas avaliações realizadas após os 12 DAE, foram verificados efeitos significativos da infestação com $T$. harzianum, porém sem influência dos fatores formas de preparo do solo e tipo de resteva (Figura 2). 
TABELA 5. Comprimento da maior haste $(\mathrm{cm})$ da planta de batata aos 12 DAE, considerando a interação entre os fatores formas de preparo e infestação do solo com T. harzianum.

Length of the longest $\mathrm{stem}(\mathrm{cm})$ of potato plants at $12 \mathrm{DAE}$ considering the interaction between the factors preparation forms and soil infestation with $T$. harzianum.

\begin{tabular}{lcc}
\hline \multicolumn{1}{c}{ Formas de preparo } & Não infestado com & Infestado com \\
& T. harzianum & T. harzianum \\
\hline Preparo-base com escarificador (P1) & $27,42 \mathrm{a}$ & $31,32 \mathrm{a}$ \\
P1 + Grade niveladora (P2) & $32,92 \mathrm{a}$ & $31,55 \mathrm{a}$ \\
PB + Enxada rotativa (P3) & $25,01 \mathrm{~b}$ & $31,72 \mathrm{a}$ \\
PB + Grade niveladora+ Enxada rotativa (P4) & $23,07 \mathrm{~b}$ & $33,60 \mathrm{a}$ \\
\hline DMS para linhas & & 5,130 \\
\hline DMS para colunas & & 11,350 \\
\hline
\end{tabular}

Médias, na linha, seguidas pela mesma letra não diferem estatisticamente entre si, pelo teste de Tukey, ao nível de 5\% de probabilidade do erro.

Verifica-se, que nos preparos P3 e P4 onde é realizado maior revolvimento do solo, as plantas apresentaram hastes menores quando não foi realizada a infestação do fungo, demonstrando que para esta característica o manejo do solo pode afetar o desenvolvimento inicial das plantas, sendo que o maior revolvimento do solo ocasionado pela enxada rotativa demonstrou ser menos adequado para a expansão das hastes da cultura. Neste caso, a atuação do fungo reduziu o efeito negativo ocasionado pelo maior revolvimento do solo. $\mathrm{O}$ efeito positivo do fungo sobre o desenvolvimento inicial da cultura pode ser ainda observado nos resultados da avaliação aos $27 \mathrm{DAE}$, em que, na presença do fungo, as plantas apresentaram maior comprimento de haste (Figura 2).

Quanto ao revolvimento do solo, os resultados estão de acordo com as observações de CARVALHO FILHO et al. (2007), que enfatizam os benefícios do preparo conservacionista, em que as operações mecânicas de manejo do solo são reduzidas, utilizando-se especialmente do escarificador. Os autores salientam que esta forma de preparo do solo mantém o índice de rugosidade mais elevado, gerando menor tendência de formação de encrostamento superficial, aumentando a quantidade de água que poderá ficar retida no solo e podendo proporcionar melhor desenvolvimento vegetativo da batata, sendo esta uma cultura com alto grau de sensibilidade no que diz respeito à umidade do solo.

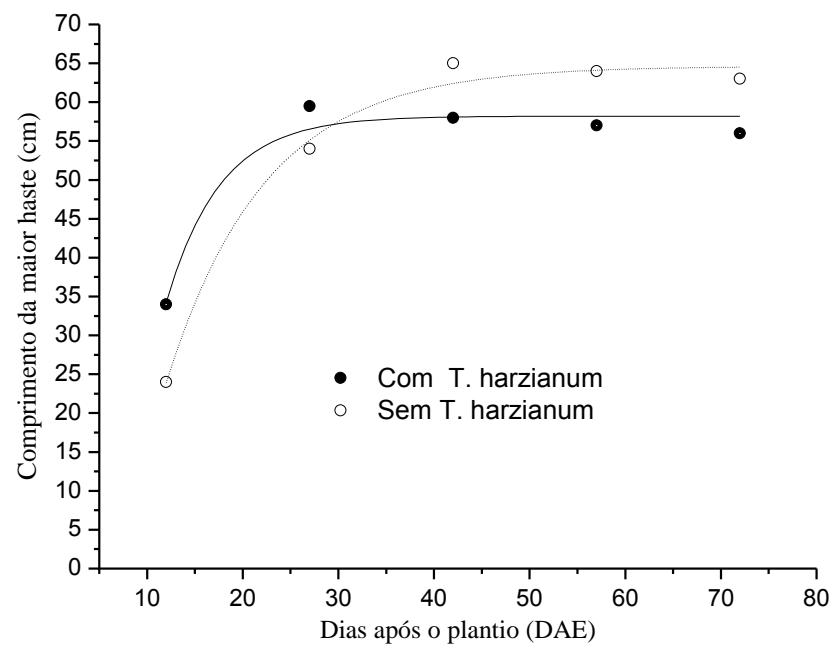

FIGURA 2. Comprimento da maior haste de plantas de batata submetidas ao cultivo sem $\left(Y=-204,2 \times e^{-X / 5,607}+58,2\right)\left(R^{2}=0,98\right)$ e $\operatorname{com}\left(Y=-130,596 \times e^{-X / 10,302}+64,62\right)$ $\left(R^{2}=0,98\right) \quad$ infestação do solo com $T$. harzianum. Guarapuava - PR. Length of the longest potato plant stem submitted to the cultivation without $\left(Y=-204,2 \times e^{-X / 5,607}+58,2\right) \quad\left(\boldsymbol{R}^{2}=0,08\right) \quad$ and with $\left(Y=-130,596 \times e^{-X / 10,302}+64,62\right)\left(\boldsymbol{R}^{2}=0,98\right)$ soil infestation with $\boldsymbol{T}$. harzianum. 
Após os 27 DAE, as plantas cultivadas em solo sem infestação com T. harzianum passam a apresentar os maiores comprimentos de hastes, chegando aos 42 DAE com hastes aproximadamente $5 \mathrm{~cm}$ mais longas. Contudo, na presença de $T$. harzianum, é possível que o menor crescimento, em comprimento, tenha sido compensado com um maior crescimento radial das hastes, pois, aos 42 DAE, o IAF é similar (Figura 1), e a diferença no comprimento de hastes não se traduz em diferenças no peso da massa seca da parte aérea. Este efeito de indução de espessamento de tecido por T. harzianum e do crescimento radial é discutido por WINDHAM et al. (1986).

Os valores médios de comprimento de maior haste verificados neste experimento são aproximadamente similares aos observados por MELO et al. (2003), que enfatizam ser a Ágata uma cultivar de batata de porte baixo. Entretanto, FERNANDES et al. (2010), estudando o comprimento da maior haste, não observaram diferenças entre a Ágata e outras cultivares, como Markies e Atlantic.

\section{CONCLUSÕES}

$\mathrm{O}$ uso da enxada rotativa não melhorou o índice de área foliar e pode ser retirado do sistema de preparo de solo para cultivo da batata; a resteva de aveia produziu menor índice de área foliar que a da cultura do milho na fase inicial do ciclo de desenvolvimento das plantas. A quantidade de massa seca produzida pelas plantas apresentou resposta inversa à intensidade de mobilização no preparo de solo. A infestação do solo com $T$. harzianum promoveu maior produção de massa seca final da parte aérea, maior IAF da planta e contribuiu para o crescimento da maior haste da planta.

\section{REFERÊNCIAS}

ALTOMARE, C.; NORVELL, W.A.; BJORKMAN, T.; HARMAN, G. E. Solubilization of phosphates and micronutrients by the plant-growth-promoting and biocontrol fungus Trichoderma harzianum Rifai. Apllied an Environmental Microbiology, Washington, v. 65, p.2926-2933, junho, 1999.

CARVALHO FILHO, A.; CENTURION, J.F.; SILVA, R.P.; FURLANI, C.E.A.; CARVALHO, L.C.C. Métodos de preparo do solo: Alterações na rugosidade do solo. Engenharia Agrícola, Jaboticabal, v.27, n.1, p.229-237, jan./abr. 2007.

COELHO, F.S.; FONTES, P.C.R.; PUIATTI, M.; NEVES, J.C.L.; SILVA, M.C.C.; BRAUN, H. Área foliar e massa seca de cultivares de batata em Área foliar e massa seca de cultivares de batata em função da adubação nitrogenada. Horticultura Brasileira, Brasília, v.27, n. 3, p.774-778. Jul./set., 2009.

DINIZ, L. Plantas de cobertura do solo no sistema de plantio direto. Parte II, ReAHgro - Artigos Técnicos, v.4, n. 1, p.11, 19, maio, 2007.

DONOSO, E.G.; LOBOS, Y.N.; ROJAS. Efecto Trichoderma harzianum y compost sobre el crecimiento de plántulas de Pinus radiata en vivero. Revista Bosque - UAC, Valvidia, v.29, n.1, p. 52-57, jan/abr. 2008.

FERNANDES, A.M.; SORATTO, R.P.; SILVA, B.L.; SOUZA-SCHILICK, G.D. Crescimento, acúmulo e distribuição de matéria seca em cultivares de batata na safra de inverno. Pesquisa Agropecuária Brasileira, Brasília, v.45, n.8, p.826-835, abr., 2010.

FERNANDES, H.A.; OLIVEIRA, A.D. de; FONTES, P.C.R.; CAMILO, A.J.; RINALDI, P.C.N. Avaliação da cultura da batata instalada por uma plantadora adaptada para trabalhar em sistemas de plantio direto e cultivo mínimo. Revista Ceres, Viçosa-MG, v.53, n.305, p.65-73, nov./dez., 2006.

FURLANI, C.E.A.; SILVA, R.P. Culturas intercaladas ao milho para produção de massa e cobertura do solo. Revista Plantio Direto, Passo Fundo, v. 113, p. 22-30, set./out. 2009. 
GHAZAVI, M.A.; HOSSEINZADEH, B.; LOTFALIAN, A. Evaluating Physical Properties of Potato by a Combined Tillage Machine. Nature and Science, New York, v.8, n.11, p.66-70, nov., 2010.

HARMAN, G.E. Myths and dogmas of biocontrol changes in perceptions derived from research on Trichoderma harzianum T-22. Plant disease, St. Paul, v.84, p.377-392, abr., 2000.

IZIDORIO, R.; MARTINS FILHO, M.V.; MARQUES JÚNIOR, J.; SOUZA, Z.M.; PEREIRA, G.T. Perdas de nutrientes por erosão e sua distribuição espacial em área sob cana-de-açúcar. Engenharia Agrícola, Jaboticabal, v.25, n.3, p.660-670, set./dez. 2005.

JADOSKI, S. O.; MAGGI, M.F.; LIMA, A.S.; BRUNETTA, L.; WAZNE, R. Sucessão de culturas na fitossanidade e produtividade da cultura da batata (Solanum tuberosum L.). Pesquisa Aplicada \& Agrotecnologia, Guarapuava, v.2, n.1, jan./abr. 2009.

JADOSKI, S.O.; MAGGI, M.F.; LIMA, A. dos S.; VIEIRA, D.J.; WAZNE, R. Evaluation of NPK 8-30-20 with gypsum addition compared to fertilization employed in the region for the production of potato (Solanum tuberosum L.) Pesquisa Aplicada \& Agrotecnologia, Guarapuava, v3, n.1. p.117-122, jan./abr. 2010.

JENKINS, P.D.; MAHMOOD, S. Dry matter production and partitioning in potato plants subjected to combined deficiencies of nitrogen, phosphorus and potassium. Annals of Applied Biology, Malden, v.143, p.215-229, out., 2003.

LISBOA, B. B.; BOCHESE, C. C.; VARGAS, L. K.; SILVEIRA, J. R. P.; RADIN, B.; OLIVEIRA, A.M.R. de. Eficiência de Trichoderma harzianum e Gliocladium viride na redução da incidência de Botrytis cinerea em tomateiro cultivado sob ambiente protegido. Ciência Rural, Santa Maria, v.37, n.5, p.1255-1260, set./out., 2007.

MARTINS FILHO, M.V.; LICCIOTI, T.T.; PEREIRA, G.T.; MARQUES JÚNIOR, J.; SANCHEZ, R.B. Perdas de solo e nutrientes por erosão num Argissolo com resíduos vegetais de cana-deaçúcar. Engenharia Agrícola, Jaboticabal, v. 29, n. 1, p. 8-18, jan./mar. 2009.

MELO, P.C.T.; GRANJA, N.P.; MIRANDA FILHO, H.S.; SUGAWARA, A.C.; OLIVEIRA, R.F. Análise do crescimento da cultivar de batata “Ágata”. Batata Show, Itapetininga, n.8, v.1, p. 14-21, dez., 2003.

SAITO, L .R. S.; SALES, L.L.S.R.; MARTINCKOSKI, L.; ROYER, R.; REFFATTI, T. Aspectos dos efeitos do fungo Trichoderma spp. no biocontrole de patógenos de culturas agrícolas. Pesquisa Aplicada \& Agrotecnologia, Guarapuava, v.2, n.3, p.203-213, set./dez., 2009.

SCHUCH, L.O.B.; KOLCHINSKI, E.M.; CANTARELLI, L.D. Relação entre a qualidade de sementes de aveia-preta e a produção de forragem e de sementes. Scientia Agraria, Curitiba, v.9, n.1, p.1-6, jan./mar., 2008.

SILVA, M.C.C.; FONTES, P.C.R.; VIANA R.G. Estimativa da área da folha da batateira utilizando medidas lineares. Horticultura Brasileira, Brasília, v.26, n 1, p.83-87, jan./mar., 2008.

SOUZA, Z.S. Ecofisiologia. In: PEREIRA, S.A.; DANIELS, J. (Ed.). O cultivo da batata na região Sul do Brasil. Brasília: Embrapa Informação Tecnológica, 2003. p.80-104.

TEIXEIRA, I.R.; SILVA, R.P.; SILVA, A.G.; FREITAS, R.S. Competição entre feijoeiros e plantas daninhas em função do tipo de crescimento dos cultivares. Planta Daninha, Viçosa, v.27, n.2, p.235-240, abr./jun. 2009.

WINDHAM, M.T.; ELAD, Y.; BAKER, R.A. Amechanism for increased plant growth induced by Trichoderma spp. Phytopathology, St. Paul, v.76, p.518-521, maio 1986. 